\title{
ISTO É UM CACHIMBO
}

\author{
Virginia Figueiredo ${ }^{2}$ \\ virginia@fafich.ufmg.br
}

RESUMO Partindo do quadro de René Magritte, La trahison des images (Ceci n'est pas une pipe), este texto pretende tecer um comentário sobre as relações entre arte e realidade. Visando esse objetivo, tentarei interpretar a obra do pintor belga à luz do ensaio heideggeriano sobre a "Origem da obra de arte”, não sem antes passar em revista alguns resultados da análise contida no livro de Michel Foucault, assim como algumas reflexões do filósofo da arte norte-americano Arthur Danto.

Palavras-Chave Magritte; Foucault; Arthur Danto; Heidegger; Arte e Realidade

ABSTRACT Departing from the painting La trahison des images (Ceci n'est pas une pipe), by René Magritte, this paper intends to comment the relationships between art and reality. Aiming this objective, I will try to interpret the work of the Belgian painter according to Heidegger's essay on "The Origin of the work of art", and also reviewing some of the results of the analysis made by Michel Foulcault in his book, along with some thoughts of Arthur Danto.

Keywords Magritte; Foucault; Arthur Danto; Heidegger; Art and Reality

1 Este trabalho resultou de pesquisa que contou com o apoio de bolsa (da CAPES) de pós-doutorado e de bolsa de produtividade em pesquisa do CNPq. Artigo recebido em 15/09/05 e aprovado em 15/11/05.

2 Professora do Departamento de Filosofia da Universidade Federal de Minas Gerais.

KRITERION, Belo Horizonte, $n^{\circ}$ 112, Dez/2005, p. 442-457 


\section{Preâmbulo}

Como não poderia deixar de ser, começo por uma breve notícia sobre o quadro que ouso comentar aqui, apesar do maravilhoso livro de Michel Foucault. Chamo a atenção apenas para o detalhe que, no título de meu trabalho, ao contrário do título do quadro $e$ do ensaio de Foucault, trata-se de uma afirmação e não de uma negação, consistindo essa afirmação propriamente no pretexto que me "obrigou" a escrever o presente texto, como se ele resultasse da necessidade de "complementar" o ensaio foucaultiano. O que pretendo discutir e o que, sinceramente, a meu ver, não era o tema do livro de Foucault, são as relações entre arte e realidade. Além disso, tentarei interpretar o quadro segundo o ponto de vista ontológico do ensaio de Heidegger sobre a "Origem da obra de arte".

Passemos então ao quadro. Trata-se de uma pintura a óleo de René Magritte $^{3}$ e que se chama La trahison des images (Ceci n'est pas une pipe). Sobre ele, haveria muitas coisas a dizer. Quanto à imagem, por exemplo, poderse-ia lembrar que o cachimbo foi uma espécie de obsessão ou tema recorrente na obra magritteana. Em 1926, o pintor já tinha feito uma primeira versão, que chamarei de "primitiva", "pré-clássica" ou ainda "pré-moderna", intitulada Sans titre (La pipe); em 1928/1929, foi pintada a "versão clássica", com a qual me ocuparei aqui e a qual passarei a denominar, para facilitar um pouco as coisas, "Traição" ou simplesmente "cachimbo clássico, moderno"; em 1966, o pintor insere o quadro "Traição" em outro quadro maior, contendo um "novo" cachimbo, que paira feito uma nuvem ou supra-realidade fora do cavalete. Essa nova pintura que constitui o foco da análise foucaultiana e que eu chamaria de pós-clássica ou pós-moderna, o próprio Magritte a designou Les deux mystères. Além disso, poderia, consultando o livro dos símbolos da psicanálise, lembrar as associações de cigarros, charutos, cachimbos assim como dos narizes, de um modo geral, com o órgão sexual masculino, ou seja, tudo o que exala (expira) ou sorve (aspira) fumaça parece estar relacionado com o phallus. Será em virtude dessa simbologia fálica que o quadro do cachimbo adquiriu tanta fama? Pois, não sei se é sabido, há outro quadro de Magritte Ceci n'est pas une

3 Como é sabido por todos, René Magritte (1898-1967) é um pintor belga, reconhecidamente um dos principais representantes do Surrealismo. Seria interessante confrontar dois pontos de vista acerca desse importante movimento da vanguarda européia: de um lado, Clement Greenberg, que julgou os artistas surrealistas como "restauradores do passado literal" e "agentes de uma nova arte conformista e voltada ao mercado"; e de outro, Walter Benjamin, no seu famoso ensaio "A obra de arte na era de sua reprodutibilidade técnica", que afirmou, ao contrário, serem "o surrealismo e o bolchevismo (...) a estrutura básica e gêmea do seu pensamento crítico.” (cf. WOOD, P. Arte conceitual. Trad. Betina Bischof. São Paulo: Cosac \& Naify, 2002, p. 17). 
pomme, pintado em 1964, que não teve, nem de longe, a mesma repercussão do cachimbo... E, no entanto, a maçã também não é uma imagem-símbolo qualquer: Eva, paraíso, pecado, Branca de Neve, sem contar a história da maçã na pintura (de Caravaggio a Cézanne) e as associações poderiam prosseguir por aí afora. ${ }^{4}$

\section{Palavras pintadas. Palavras como imagens}

Quanto à presença das palavras nos quadros de Magritte, haveria outra porção de coisas a contar. Eis aí um pintor que explora, como talvez nenhum outro, a relação não só entre palavra e coisa, mas também entre palavra e imagem. Poderíamos até atribuir a Magritte o apelido de "O pintor das palavras e das coisas". Em sua pintura, as palavras exercem múltiplos papéis e têm várias funções. A primeira e principal função, pressuposta nas demais, assumida pelo próprio pintor, é a função de imagem. Lembro que a inscrição “Ceci n'est pas une pipe" está pintada no próprio quadro de 1928/1929, e que são de Magritte as seguintes palavras, confundindo a clássica distinção entre as palavras e as coisas: "Num quadro, as palavras são da mesma substância que as imagens". 5 Mas ele poderia muito bem ter dito: "Num quadro, as palavras são da mesma substância que as coisas, isto é, imagem”.

\section{Palavras no lugar das coisas. Palavras como coisas}

A segunda função é a de substituição da imagem, como são os casos de $L e$ masque vide, onde um ciel, um corps humain e uma forêt substituem as imagens pintadas de um céu, um corpo humano e uma floresta, respectivamente. Vejamos quais são os efeitos mais imediatos dessa substituição. Tanto podemos pensar em um pintor, um pouco preguiçoso e desanimado com seu ramerrame, aprimorando apenas a arte da caligrafia que, em certo sentido, é bem mais fácil do que a pintura das coisas; mas podemos pensar, no ponto extremo oposto, em um pintor que, desejoso de tornar suas imagens quase infinitas, propõe ao espectador que ele pinte na sua imaginação as imagens, cujas palavras estão

4 Por último, cabe mencionar a nota do tradutor para o português, Jorge Coli, sobre a expressão, em francês: "nom d'une pipe", em FOUCAULT, M. Isto não é um cachimbo. Trad. Jorge Coli. Rio de Janeiro: Paz e Terra, 1988. p. 19-20: 'Literalmente 'nome de um cachimbo', expressão corrente, eufemismo que substitui a exclamação 'nom de Dieu' (nome de Deus), considerada na França como pesada blasfêmia. Um pouco da maneira como o nosso 'puxa vida' substitui 'puta vida'. No entanto, a ausência de semelhança entre a palavra 'Dieu' e a palavra 'pipe' (ao contrário do que acontece no exemplo dado em português) sugere que a substituição se fez pela facilidade de pronúncia do substituto..."

5 FOUCAULT. Isto não é um cachimbo, p. 51. 
previamente dispostas (e pintadas) em seu quadro... Pois, a imagem do céu vai poder variar do azul ao cinza tempestuoso, passando pelos tons avermelhados da aurora e do poente, dependendo do humor do espectador; o corps humain, por sua vez, poderá adquirir forma de mulher, homem, criança, idoso, jovem etc... e assim por diante, pois a cadeia das associações mentais, invisíveis, é sempre muito mais extensa do que a cadeia material do visível.

Reduzir objetos a nomes ou, em um gesto aparentemente infantil, pintar palavras constituiu uma estranha atitude, que talvez tenha influenciado movimentos vanguardistas posteriores como, por exemplo, a Arte Conceitual, o Kitsch e a Pop-art. Apesar dessa estranheza irreverente, a revolução magritteana não atingiu o espaço que, nos seus quadros, foi mantido em uma disposição bastante tradicional. ${ }^{6}$ Poderíamos, também, interpretar a decisão de pintar palavras, em vez das próprias coisas, como tentativa de denunciar (ou mesmo criticar) a nossa experiência cotidiana no mundo moderno que, fundada no privilégio da linguagem conceitual em detrimento de uma relação mais imediata e sensível com as coisas, acaba por tornar nossa vida tremendamente monótona ou completamente "cinza" (para usar uma metáfora usual e pictórica) como é, aliás, a cor que colore o fundo desse quadro, de onde mal se distinguem as citadas massas disformes.

\section{Palavras críticas. A ironia das palavras}

A partir do já exposto sobre as palavras, pode-se dispor as duas funções anteriores - a primeira (palavra como imagem) e a segunda (palavra no lugar da coisa) - como se fossem etapas de um mesmo processo de crescente desreferencialização, acirramento do devir-coisa que culminaria com uma rebelião total das palavras contra a sua função tradicional de representação. As palavras, nesta última função (ou etapa), completamente liberadas do seu papel tradicional de porta-significação, viriam a manter uma relação conflitante ou de resistência contra a sua essência instrumental reduzida a nome das coisas. Esta seria, sem dúvida, uma possibilidade de interpretar o caso do "nosso" cachimboclássico; e o comentário "Isto não é um cachimbo" não seria mais do que uma

6 Cf. FOUCAULT. Isto não é um cachimbo, p. 48. Outro exemplo dessa disposição tradicional é o quadro L'espoir rapide, que eu descreveria como uma distribuição de manchas com aparência volumosa, sobre as quais estão escritas palavras-objetos (ou "porta-palavras" como Foucault adequadamente as denominou): nuvem, cavalo, árvore, cidade no horizonte e bueiro de chumbo. Ali se pode constatar que essas massas espessas e muito mais substanciais do que nuvem, cavalo etc.estão distribuídas segundo uma ordem clássica do espaço do quadro. Assim, a nuvem está no alto, o cavalo no "chão", quero dizer, no canto à direita do quadro, e há mesmo uma paisagem (urbana) desenrolando-se "ao fundo", no horizonte, como em uma pintura renascentista. 
ironia com aquele "velho hábito de linguagem que toma a imagem pela própria coisa". ${ }^{7}$ Lembrando ainda que, de acordo com a definição romântica, a ironia tem uma essência deslizante (quase paradoxal, eu diria) que habita um ponto de indiferença entre o real e o ideal. ${ }^{8}$ Como observa Márcio Suzuki, "[a ironia] é inteiramente uma coisa e, ao mesmo tempo, inteiramente outra."9

\section{Transposição filosófica do problema}

Se sairmos da imanência da obra rumo à transposição, que chamarei arrogantemente de "filosófica", daquelas três etapas (já descritas) da relação entre as palavras e as coisas, poderíamos reescrever historicamente os três momentos, redistribuindo os três cachimbos, em um encadeamento ou seguindo um critério linear e cronológico ou segundo um ponto de vista hermenêutico e estilístico. Julgo que teremos melhores resultados se adotarmos de preferência este último modo de apresentação, o hermenêutico, a que chamarei também de "perspectivista". E aí, teremos respectivamente: o primeiro momento, platônico ou clássico da representação, cuja imagem correspondente nos forneceria o modelo clássico ("moderno" — La trahison...) do cachimbo; o segundo momento, da crítica ou ruptura do mecanismo da representação (cuja imagem emblemática seria a versão pós-moderna e irônica — Os dois mistérios, por exemplo); e finalmente, o momento de reversão do platonismo ou glorificação da arte encontraria sua imagem na versão pré-moderna, primitiva "La pipe".

\section{Momento Platônico ou Clássico - La trahison}

A perspectiva do primeiro momento leva a sério o comentário (na verdade, irônico) de Magritte e conclui com a obediência do pintor não só à concepção platônica da arte, mas também ao papel tradicional (de designação ou representação) das palavras. Aqui "platonismo" deverá ser entendido, abrupta e grosseiramente, enquanto uma concepção da essência da arte como ilusão ou cópia da cópia; isso quer dizer que a pintura, na sua realidade de "superfície

7 FOUCAULT. Isto não é um cachimbo, p. 20.

8 Cf. SUZUKI, M. O gênio romântico. São Paulo: Ed. Iluminuras, 1998. p. 178.

9 Na seqüência dessa passagem, Suzuki cita Schlegel descrevendo a ironia socrática: "A ironia socrática é a única dissimulação inteiramente involuntária e, no entanto, inteiramente lúcida. Fingi-la é tão impossível quanto revelá-la. Para aquele que não a possui, permanece um enigma, mesmo depois da mais franca confissão. Não deve enganar ninguém, a não ser aqueles que a tomam por engodo e que, ou se alegram com a grande pândega de se divertir com todo mundo, ou ficam fulos, quando pressentem que também estão sendo visados. Nela tudo deve ser gracejo e tudo deve ser sério: tudo sinceramente aberto e tudo profundamente dissimulado." (SCHLEGEL, F. Lyceum 108. Kritische Ausgabe, II, p. 160, apud SUZUKI. O gênio romântico, p. 178). 
preenchida unidimensionalmente por cores", não tem o menor direito de reivindicar qualquer estatuto ontológico. A cama pintada jamais poderia ter realidade (ou verdade), para Platão, na medida em que apenas a Idéia é essencialmente real, como todo mundo já sabe. Segundo essa hierarquia, à cama pintada não é concedido sequer compartilhar da realidade que tem a cama do marceneiro, sobre a qual se pode seguramente dormir, já que a utilidade sempre foi um critério inquestionável de valor das coisas. Estamos, por conseguinte, no ambiente clássico da representação. E Magritte, concordando com o irredutível Platão, sussurra: "O famoso cachimbo... Como fui censurado por isso! E, entretanto... Vocês podem encher de fumo o meu cachimbo? Não, não é mesmo? Ele é apenas uma representação. Portanto, se eu tivesse escrito no meu quadro: 'isto é um cachimbo', eu teria mentido."10

\section{A incrível vigência dos conceitos platônicos para pensar a questão da arte e, sobretudo, a relação entre arte e realidade!}

Permanecendo ainda nesse primeiro momento, é preciso reconhecer que talvez tenha sido Platão quem forjou os principais conceitos ainda hoje em vigor para pensar a questão da arte, pelo menos no tocante ao problema da relação entre arte e realidade. É impressionante! Em certo sentido, a essência de ilusão de toda arte, de toda mimesis foi mais radicalmente compreendida (senão mesmo temida) por Platão do que pelo próprio Aristóteles, que, posicionando-se, inicialmente, a favor da arte, nem chega a problematizar a questão, como diz Danto, "mudando logo de assunto". Talvez tenha sido a Poética a primeira apreensão filosófica da arte, ${ }^{11}$ aquela que concedeu o direito de cidadania à arte, isso quer dizer, no entanto e infelizmente, que essa operação não é feita sem que um tributo seja pago, que é o do controle e da domesticação filosófica da arte. Sem querer aprofundar o problema do estatuto ou essência (subversiva talvez) da arte e do prazer que a ficção suscita, Aristóteles "muda de assunto", encontra um lugar adequado ao prazer com a arte, conferindo-lhe um valor pedagógico e funcional. ${ }^{12}$ É então necessário esclarecer esse efeito

10 René Magritte, citado na contra-capa da $3^{\underline{a}}$ edição brasileira de FOUCAULT. Isto não é um cachimbo.

11 Sem condições de situar precisamente o texto no qual aprendi essa lição, posso afirmar com certeza que ela provém das reflexões de Philippe Lacoue-Labarthe sobre arte, política e filosofia.

12 Lendo o capítulo 4 da Poética de Aristóteles, Danto interpreta também naquele mesmo sentido: "Part of the pleasure surely is due to the knowledge that it is not really happening, and not because we learn from the imitation, as Aristote goes on to say, seeming to give na explanation but actually changing the subject." (Parte do prazer é obtido, com certeza, do conhecimento de que nada está acontecendo realmente, e não porque aprendemos alguma coisa com a imitação, como Aristóteles continua a dizer, parecendo dar uma explicação mas na verdade mudando de assunto). DANTO. Works of art and mere real things. In: The Transfiguration of the Commonplace. Cambridge, Massachusetts/London, UK: Harvard University Press, 1981. p. 15. (grifos no original) 
paradoxal: se a identificação platônica da arte com o simulacro provocou o gesto, sem dúvida, brutal e negativo, o gesto celebérrimo da expulsão do poeta da pólis, por outro lado, esse modo de conceber a arte, não deixa de ter uma contrapartida positiva, na medida em que reconhece a potência ou a intensidade afinal política da arte. Ou seja, exatamente porque considera a arte pelo seu caráter politicamente "perigoso"13 é que Platão prefere a atitude da evitação e da distância com relação a ela, recusando-lhe, portanto, o direito de cidadania, inquestionavelmente conferido pela Poética de Aristóteles. Talvez, arte radical seja aquela que hoje ainda é capaz de resgatar esse valor de resistência da ilusão, do mundo que não é útil e que desafia a realidade imediata das obrigações e interesses (atualmente os do mercado). Talvez arte radical seja aquela ainda capaz de se apoderar de sua origem política, revertendo e demolindo as fronteiras disciplinares que asseguram a separação entre arte, política e filosofia, rebelando-se contra o efeito inevitável de neutralização que resulta daquela "disciplinarização".

O fato de ter escolhido comentar uma obra de um pintor como Magritte não tem qualquer intenção normativa e nem pretende sugerir que se trate hoje de repetir a "experiência surrealista", cuja principal característica talvez tenha sido justamente a tentativa de apagar os limites entre arte e vida. Mas de uma coisa tenho certeza, do lado no qual nos encontramos, ou seja, do lado do questionamento, do lado inevitavelmente teórico (e não prático do fazer arte), a pergunta sobre a relação entre arte e política que julgo urgente se fazer, hoje e... sempre, passa de maneira necessária por um questionamento sobre as relações entre arte e realidade. Poderíamos fazer essa pergunta sobre as relações entre arte e realidade a muitos artistas ou teóricos diferentes. ${ }^{14}$ Diria que a

13 Para confrontar com essa visão platônica da arte como eficiência e perigo, recordo aqui o início do artigo de A. Danto "The philosophical Disenfranchisement of Art" (New York: Columbia University Press, 1986, p. 1), que recorre, por sua vez, ao poema de W. H. Auden, escrito por ocasião da morte de W. B. Yeats: "Agora a loucura e o clima da Irlanda aquietaram-se, pois a poesia nada faz acontecer". "É claro", comenta Danto, "que ninguém, nem mesmo o poeta visionário, esperaria que poemas líricos pudessem diminuir a umidade da Ilha Esmeralda e daí foi concedido a Auden seu paradigma de impotência da arte." ("No one, I suppose, not even a poetic visionary, would have expected lyrics to dispel the humidities of the Emeral Isle, and this gives Auden his paradigm of artistic impotency.")

14 Recentemente, aprendi com a tese de Bruno Almeida Guimarães, que será defendida em breve no Programa de Pós-graduação em Filosofia da UFMG, que Lacan afirmava (Seminário VII: a Ética da psicanálise) que o nosso único meio de acesso à realidade é a ficção. O que promove indubitavelmente a arte, conferindoIhe uma função política de extrema importância. Ainda nesse contexto "discente", em comunicação pessoal com outro doutorando, Pedro Dolabela, este lembrou que W. Iser, teórico da Estética da Recepção, não só concordaria com a afirmação de Lacan (que pronuncia essa idéia em um contexto de análise das teses de Jeremy Bentham), como Ihe acrescentaria que a diferença entre as outras formas discursivas e a arte reduz-se apenas ao fato de que esta última, ao contrário das outras, assume-se enquanto tal, enquanto ficção. A arte traria inscrita em si mesma a diferença entre o simbólico e o real, entre as palavras e as coisas etc., obscurecida e velada nas demais formas discursivas. 
escolha de Magritte, assim como a desse quadro (ou série dos quadros representando cachimbos), talvez se deva a um mero acaso ou porque eles se prestaram mais claramente a esse tipo de questão. Ninguém ousará objetar que Ceci n'est pas une pipe não nos incita a pensar, entre muitas outras, mas talvez de forma privilegiada, nas relações entre arte e realidade.

Voltando ao nosso argumento, a conclusão desse primeiro momento seria a da possibilidade de interpretar o quadro La trahison segundo um modelo platônico, no qual a obra de arte, enquanto mera ilusão, não pode reivindicar qualquer realidade. As palavras, no quadro, ainda mantêm inquestionada sua função tradicional, isto é, sua função referencial e, por conseguinte, estão obrigadas a dizer a ... Verdade: "Isso não é um cachimbo!" Mas, justamente lembrando aquela ambigüidade da posição platônica diante da mimesis, ou seja, do valor de perigo, ao qual acabo de me referir, o quadro não sossega, há sempre algo que sobra, que resiste, mesmo na mais clássica (mais obediente) das representações e que nos obriga a tentar uma outra perspectiva. Passo então ao segundo momento.

\section{Excurso sobre Danto ou Da cama de Rauschenberg à cama de J}

Julgo que uma das principais questões com a qual a Estética de Arthur Danto se confrontou foi exatamente a da relação entre arte e realidade. Talvez pudéssemos justificar a sua preocupação profundamente política ${ }^{15}$ através do contexto ou momento histórico no qual sua obra crítica está inserida. Não tenho a menor idéia se ele concordaria com este epíteto, mas, no meu modo de ver, ele é " $O$ filósofo da Pop-Art", sintetizando-se aqui grosseiramente sob o nome "Pop-Art" a produção norte-americana de arte a partir do final dos anos 1950 e início dos anos 1960), da qual, talvez, ele mais do que qualquer outro, tentou extrair o aspecto crítico, diminuindo a margem ambivalente, a do elo inegável, para muitos outros críticos, motivo de uma condenação irreparável, com o mercado e com a indústria cultural. Sabe-se o quão pequena foi a diferença que a maioria dos críticos viu entre o movimento da Pop-Art e a

15 E não receio atribuir a qualidade de "política" à preocupação com a relação entre arte e realidade, pois, entre outras questões que derivam daquela relação "maior ou principal" está, por exemplo, a que diz respeito à eficácia da arte, da qual, por sua vez, decorrem perguntas tais como: Terá a arte força suficiente para intervir na realidade? O que poderíamos chamar de uma "arte revolucionária"? Aquela que seria capaz de transformar a realidade? Não conseguimos identificar claramente a tonalidade "política" dessas perguntas? Será que teríamos algum proveito em reduzir a relação arte e realidade (âmbito histórico, empírico, do-ne qual inegavelmente "transcorre" a política) à "brecha" ou "diferença" (em certo sentido, insuperável) entre o transcendental e o empírico? 
propaganda direta. ${ }^{16}$ Ainda no meu modo de ver, Danto tenta pôr a produção da arte contemporânea dos norte-americanos em sintonia com os movimentos da vanguarda européia do início do século XX. Se não em "sintonia", talvez em busca de um "lastro" ou de uma legitimação histórica, visando à conquista de um lugar na história mundial (internacional) daquela produção. Tratava-se, a meu ver, portanto, de um possível processo de "internacionalização" da arte norte-americana, da chamada mudança de referencial, de Paris para Nova York. Nada mais "político", portanto. Não é à toa que ele põe em diálogo, de modo recorrente, artistas como Andy Warhol e o francês Marcel Duchamp (18871968).

A questão dos "pares indiscerníveis" (Brillo Box de Warhol, a pá de neve de Duchamp) ou, em outras palavras, a questão inaugurada por Duchamp e seus ready-mades ${ }^{17}$ (dos quais Fountain é exemplar, e todo mundo já conhece essa história ${ }^{18}$ ) não era apenas a proibição do prazer estético com o belo ainda que não se possa totalmente ignorar esse efeito imediato do readymade (que tentou lançar a última pá de cal sobre o belo) - mas principalmente o reconhecimento de um problema, que chamaria d'A questão duchampiana, e Danto desempenhou aí o importante papel de sublinhá-la, que consistiu em indicar a marca distintiva ou o traço específico da obra de arte contemporânea como sendo aquela necessidade de incluir nela mesma a questão (problema ou pergunta) de sua origem ou essência. Portanto, a meu ver, uma das teses importantes de Danto ${ }^{19}$ sobre a arte moderna (não se esqueça: a famosa Fountain é de 1917) e contemporânea, ele a enuncia ao examinar os "pares indiscerníveis", de um lado, de Duchamp (Fountain ou as Pás de neve), de outro, de Warhol (a Brillo Box). Repetindo: a arte contemporânea teria de

16 Cf. MCCARTHY, David. Arte Pop. Trad. Otacílio Nunes. São Paulo: Cosac \& Naify, 2002. p. 35.

17 Cf. WOOD. Arte conceitual, p. 12: "O primeiro 'readymade sem assistência' de Duchamp foi um suporte de metal para garrafas (1914). Apesar de sua alegação de que a escolha do objeto tinha sido arbitrária, talvez ele tenha optado por algo bastante próximo do tipo de elementos que começavam a emergir como formas escultóricas, com o objetivo de forçar a questão sobre o que era e não era arte - onde terminava o domínio do estético e começava o do utilitário."

18 Ibidem, p. 12: A história da Fonte: "Duchamp, então um artista bem-estabelecido, era um dos membros do comitê de seleção em uma exposição aberta de esculturas em Nova York. Comprou um urinol numa loja de ferragens e o submeteu como escultura - assinada com o pseudônimo 'R. Mutt' - aos outros membros do comitê. A obra foi rejeitada pelo júri - apesar do suposto caráter aberto da exposição, acessível a qualquer um que pagasse a taxa de inscrição - e não foi exibida. As alegações eram de que a obra era de certo modo 'moral'; de que se tratava 'simplesmente' de uma peça de banheiro, e assim por diante. A questão se fez ainda mais seriamente cômica pela semelhança formal entre o urinol e as esculturas abstratas organicamente moldadas de Constantin Brancusi, algumas das quais já tinham sido expostas nos Estados Unidos."

19 Com certeza não foi Danto que enunciou originalmente essa tese. Conceda-se a ele pelo menos o fato de haver enfatizado esse problema (como a característica talvez essencial da arte moderna e contemporânea) que ele compartilha com muitos outros filósofos da arte. Só para citar alguns: Adorno, W. Benjamin, Heidegger. 
absorver em sua própria estrutura uma dimensão filosófica, reflexiva. É apelando para a consciência de uma diferença que, ainda no meu modo de ver, Danto resolve o problema dos "pares indiscerníveis". Mas qual será mesmo a diferença entre o objeto que está na realidade (no supermercado, na loja de materiais de construção etc.) e o que tem, sendo arte, o "direito" de estar exposto nas galerias ou nos museus? Esta pergunta não para de nos assediar. É possível que, inesperada e surpreendentemente, encontremos uma convergência entre a solução de Danto e os resultados da análise heideggeriana do quadro de Van Gogh. Voltarei a esse ponto mais adiante.

Por enquanto, constatemos que é ainda o velho Platão que Danto convoca para tentar discernir "Works of art and mere real things" 20 e conclui que: "Seria possível ler a história inteira da arte (...) como uma resposta (...), imagina[ndo] que os artistas dedicaram-se a uma espécie de promoção ontológica, que significa, claro, a superação da distância entre a arte e a realidade, subindo um grau na escala do ser." ${ }^{21}$ Promover ontologicamente a arte parece realizar então a reversão do platonismo, tão ansiada por Nietzsche e seus seguidores. Danto analisa a Cama do artista norte-americano, Rauschenberg, como uma paródia, em evidente resposta ao exemplo da República X. Ele então a descreve: tratavase de uma cama, na qual, certamente, ninguém podia dormir, já que estava presa no alto de uma parede e toda besuntada de tinta. E Danto continua falando, inspirado por outras camas: uma que foi feita mais ou menos na mesma época, por Claes Oldenberg ${ }^{22}$ — versão horripilante confeccionada de plástico que transformaria a simples experiência de dormir em um verdadeiro horror, mas, nada mal para um artista, se a brecha entre ele e o marceneiro é tão vasta quanto Platão supôs. O último passo do diálogo entre Danto e Platão é dado por um artista fictício "J"23 que, segundo Danto, teve de percorrer uma enorme distância (justamente entre a arte e a realidade) a fim de tornar possível a "transformação" (será que Danto diria aqui "transfiguração"?) de sua própria cama (a mesma na qual ele dormia todos os dias) em uma obra de arte, sem qualquer manchinha de tinta. Sua cama tal e qual, sem uma gotinha sequer de tinta, ao contrário da cama de Rauschenberg. Este último saturou supersticiosamente a sua cama de tinta, talvez para tornar claro que se tratava

20 Esse é o título do primeiro ensaio do livro de DANTO. The transfiguration of the commonplace. Canadá: Library of Congress, 1981.

21 DANTO. Works of art and mere real things, op.cit., p. 12.

22 "Claes Oldenberg apresentou aos nova-iorquinos, pela primeira vez, sua escultura-pop numa performance intitulada A loja, em dezembro de 1961. Na frente de uma loja real na Lower Manhattan, ele vendeu comida e roupas de gesso (...), expandindo desse modo, como observa um tanto ironicamente David McCarthy, seu papel como artista ou produtor para incluir também o de vendedor." (Art Pop, p. 34)

23 O ensaio de Danto "cria" um artista contemporâneo imaginário chamado "J". 
ainda de uma obra de arte. "J" pode e deve dizer então sobre a sua cama que ela não é uma imitação de nada: ela é a cama. Sem dúvida, ela foi feita pelo marceneiro, mas embora tenha sido feita pelo marceneiro, foi $\mathrm{J}$ que a tornou obra de arte, e na medida em que camas exatamente iguais àquela são camas e não obras de arte, estar à altura do marceneiro, em todo caso, não seria considerado um sucesso filosófico, qualquer que tenha sido o sucesso da cama de $\mathrm{J}$ como obra de arte. ${ }^{24}$

Estou quase certa de que Danto, ao colocar seu artista fictício J para dizer "que a sua cama não é imitação de nada: ela é a cama", tem em mente a passagem do ensaio sobre a "Origem da obra de arte", quando Heidegger, no início da segunda parte, com as mesmas palavras, apelando para o exemplo do templo grego, afirma "no mais puro estilo da decisão": 25 "Uma obra de arquitetura um templo grego — não é imitação de nada". A única diferença que apontaria aqui entre Heidegger e Danto é a do tom: irônico ao extremo, no caso de Danto; quase trágico, no caso de Heidegger.

\section{Segundo momento: da crítica ou da ironia}

Após o breve excurso feito, retomo a pista da fumaça do cachimbo, mas serei brevíssima na descrição deste segundo momento. Aqui, tentarei valer-me do princípio da ironia, que mencionei um pouco antes, por considerá-lo o mais adequado para interpretar o quadro de 1966, que se chama Les deux mystères. A meu ver, Magritte aqui eleva exponencialmente a operação crítica ou irônica. E por quê? Explico: Como se não bastasse a invasão das palavras (já ocorrida em 1928, no "Traição"), cujo efeito mais estridente consistira na insinuação de outro plano (o da realidade) que, vindo de fora, comentava $e$ julgava a imagem: "Não, isso não é um cachimbo". Ao duplicar a própria imagem do cachimbo, em 1966, estaria Magritte constituindo mais um novo plano? Da transcendência? Reparem que a "segunda" imagem paira um pouco acima, e essas disposições espaciais estão longe de ser insignificantes, lembremos que as palavras (no quadro de 1928/1929) ocupavam a parte de baixo, como uma legenda. Agora, a nova imagem flutua como uma nuvem, sem qualquer apoio e, ao contrário do plano verbal, que entrara — de fora para dentro sorrateiramente por baixo da porta do quadro, o plano das alturas parece ter-se

24 Esse último parágrafo é uma mistura de paráfrase com tradução do ensaio de DANTO, Works of art and mere real things, op. cit., p. 12-13.

25 LACOUE-LABARTHE, Ph. A vera-semelhança. Trad. Nina de Melo Franco. In: DUARTE, R.; FIGUEIREDO, V. (Org.). Mimesis e Expressão. Belo Horizonte: Editora UFMG, 2001. p. 16. 
originado na própria imanência (como a fumaça que vem depois da baforada), isto é, do próprio interior do quadro, do cachimbo, eu diria, e mais uma vez "comenta-o" silenciosa, soberana e misteriosamente. Já não se trata mais, como no primeiro caso, da objeção realista, proveniente da realidade empírica, utilitária a recusar o estatuto ontológico ao cachimbo pintado. Agora, é como se um terceiro plano (transcendental?) se abrisse assim de modo abrupto e, forma pura do espaço, passasse a sugar toda a matéria da realidade. Les deux mystères jamais poderia ser classificado como uma representação realista. Momento crítico da crítica. Ousaria dizer: transcendental.

A imanência do quadro é cindida. Heidegger e Danto apresentam duas soluções, dois caminhos, pelo menos, a meu ver, de interpretação. Mesmo que digam a mesma coisa, como afirmei acima, um sobre o templo, outro sobre a cama, a diferença de tom é evidente. O primeiro caminho segue em direção de um difícil diálogo com a tradição filosófica, "lamentando a 'notável fatalidade' à qual ficaram submissas 'desde os gregos até hoje' toda a meditação sobre a arte e a obra de arte" 26 . Heidegger, portanto, ao dizer que o templo não está no lugar de nada nem pretende representar nada, está se confrontando com a fatalidade de a reflexão sobre a arte no Ocidente ter se cristalizado em torno da noção de mimesis. Muito menos grave é o tom de Danto, irônico por excelência, que parece, na verdade, fazer uma reversão somente lógica do platonismo. A sua solução consistirá em uma resposta que, deslizando na superfície das palavras, desnudará a realidade como apenas mais uma miragem. A imensa distância entre arte e realidade é percorrida com a rapidez de um peteleco leviano, como faz o artista J.

Se adotamos a perspectiva estritamente lógica, a conclusão desse segundo momento é que, sendo a frase "Isso não é um cachimbo" essencialmente irônica, ela é ao mesmo tempo verdadeira e falsa. Como dizia Suzuki, sendo a ironia o ponto de indiferença entre o real e o ideal, ${ }^{27}$ "ela é inteiramente uma coisa e, ao mesmo tempo, inteiramente outra." A frase, então, poderia enunciar que "Isto tanto é quanto não é um cachimbo" ou simplesmente "Isto é $e$ não é um cachimbo". Ambivalente por excelência, esse momento, além de provisório, nada pode decidir. Por isso, passo logo ao terceiro e último momento de minha exposição para tentar explorar ainda os sentidos possíveis da afirmação: "Isto $e$ um cachimbo", segundo a tonalidade mais grave da interpretação heideggeriana, mas concordando com a afirmação de Danto de que se trata de uma "promoção ontológica da arte" ou, nas palavras de Nietzsche, de uma reversão do platonismo.

26 HEIDEGGER apud LACOUE-LABARTHE, op. cit., p. 15.

27 Cf. SUZUKI.O gênio romântico, p. 178. 


\section{Breve história da relação entre arte e realidade e de como ela chegou ao fim com Heidegger...}

É verdade que podemos analisar o desenrolar da história da arte seguindo diferentes fios condutores e que um desses fios, e de não pequena importância, é constituído pela relação entre arte e realidade. Aceitando seguir esse fio, a primeira experiência, quase mítica, da arte supunha uma eficiência dela sobre a realidade, há muito tempo perdida. $\mathrm{O}$ sentido do ingênuo caçador primitivo, que realiza, na realidade, os passos e movimentos que ele sabe necessários para capturar sua presa, é claro, é irrecuperável. Nunca mais acreditaremos nisso, a Aufklärung (ou a "Sobriedade Junoniana", como dizia Hölderlin) já nos constitui de um modo (natural, espontâneo e) irreversível. Há muito tempo, a nossa natureza esclarecida tornou-se conceitual. Entretanto, por mais esclarecidos que nos consideremos, não ignoramos a força da imagem e da representação, nem que seja por seu inegável valor de evocação da própria presença, da própria coisa. Com isso já poderíamos alegar uma certa falsidade da frase "Isto não é um cachimbo", na medida em que pelo menos uma das qualidades do cachimbo, a de ser vista, está até muito bem efetivada/realizada no quadro. E, se conhecer, continuando a alegação em favor da "falsidade", em uma das formulações canônicas ${ }^{28}$ da história da filosofia, significa apropriarse, ter acesso à forma das coisas, então, é inobjetável que aquela do quadro é $\mathrm{A}$ forma típica, clássica do cachimbo. ${ }^{29}$ Mesmo que não possamos soltar algumas baforadas com o cachimbo pintado por Magritte, e que, sob esse ângulo, tenhamos de concordar com Platão (e, como vimos, com o próprio pintor) que a imagem tem uma outra (o que já é melhor do que dizer "inferior") realidade diferente da realidade útil ou adequada com a sua essência fumegante, talvez seja difícil recusar alguma utilidade à imagem pintada, por exemplo, a função descritiva, indicativa. Não terá sido esse mesmo, como já foi mencionado, um dos argumentos aristotélicos sobre a origem do prazer na Poética IV, do reconhecimento ("Isto é tal")?

Mas, tentando interpretar o quadro de Magritte segundo o ensaio heideggeriano sobre a origem da obra de arte, precisarei dar mais um passo além da função epistemológica e pedagógica adquirida desde a época do Estagirita. É no sentido de uma "promoção ontológica", da qual falava Arthur Danto, ou de uma reversão do platonismo, que tento ler o famoso ensaio de

28 Cf. palestra de Oswaldo Porchat na FAFICH/UFMG em agosto de 2004.

29 Até nas lojas de produtos de umbanda no Mercado Central em Belo Horizonte aquela forma é reconhecida como típica e, querendo comprar um cachimbo igual ao do quadro, não tive dificuldade de encontrá-lo, perguntando à vendedora se ela tinha "um cachimbo bem tradicional..." 
Heidegger. Assim, retomando os resultados da célebre análise aí contida sobre o quadro de Van Gogh, acho que se pode concluir que os sapatos no quadro dizendo enfaticamente: a imagem pictórica dos sapatos de Van Gogh -, exatamente porque escapam da utilidade, possuem um valor ontológico, muitas vezes superior a qualquer sapato da realidade. São os sapatos do quadro de Van Gogh que nos tornam aptos a, retornando à experiência cotidiana, atribuir algum sentido a ela. São os sapatos pictóricos que "salvam" do naufrágio, do afogamento da cotidianidade os sapatos reais. A realidade das relações de utilidade e finalidade faz submergir todos os objetos do nosso mundo. Não é o caso de aqui trazer todas as passagens tão famosas do ensaio heideggeriano. Cito, apenas para lembrar, uma pequena seleção de alguns trechos:

Quanto menos atenção a camponesa dedica a eles [aos sapatos] em seu trabalho, mais eles se prestam ao serviço de alguma coisa, mais correspondem ao seu ser (...) É provável (...) que só possamos entender o ser do instrumento porque ele está sendo observado no quadro. A camponesa, ao contrário, ao desatar os laços de seus sapatos, em meio à fadiga do crepúsculo, para voltar a usá-los quando vem a aurora, não pensa em sua utilidade: usa o par de sapatos, simplesmente porque neles confia, e nada mais. (...) Chegamos à essência do instrumento. Mas não a descobrimos, descrevendo um par de sapatos de camponês que existe na realidade, explicando de que forma foi fabricado, ou ainda examinando a sua utilidade. Descobrimos a essência do instrumento servindo-nos da contemplação de uma obra de Van Gogh. Esta se expressou. Colocamonos em sua presença e repentinamente deslocamo-nos para outra dimensão: a obra de arte nos revelou toda a realidade do par de sapatos. Não se deve pensar que a pintura desses sapatos seja uma simples descrição subjetiva, onde posteriormente surgiria seu ser instrumento, e muito menos que ela seja uma representação intuitiva do próprio instrumento. Este se torna presente, realiza seu aparecer através da obra e somente na obra. O que, então, está agindo aí? O quadro de V. Gogh é a abertura (die Eröffnung) daquilo que profunda e verdadeiramente é o instrumento. O ente, que é o par de sapatos, nos é revelado em toda a não-ocultação de seu ser. Este estado de não-ocultação (die Unverborgenheit) os gregos chamavam de $\alpha \lambda \eta \tau \varepsilon 1 \alpha^{30}$

O que estaria então chamando de "reversão do platonismo" consistiria nesse valor ontológico mesmo, que Heidegger concederia à arte em detrimento da realidade cinzenta do nosso mundo cotidiano, seu caráter "ôntico". No quadro, o "Aberto" [das Offene] revela até mesmo o sentido do instrumento que se torna inaparente na rotina. "Reversão do platonismo" aqui significa, por exemplo, que o sapato pintado ocupa, em uma suposta hierarquia ontológica dos entes, o primeiro lugar, aquele mesmo onde Platão localizava a idéia, no famoso exemplo da cama (República X). E por que o quadro teria esse

30 HEIDEGGER, M. A origem da obra de arte. Trad. Maria José Rago Campos. Kriterion, n. 76, p. 205-207, jan.-jun. 1986. 
privilégio? Exatamente porque ele é revelador. Ele revela a essência não só do que é, de ser ele mesmo uma obra de arte, mas também a essência do outro (no nosso caso, do sapato que está na realidade). Sendo manifestação da diferença entre ser e ente, da chamada "diferença ontológica", obra de arte é também o que Heidegger chama de "acontecimento da verdade", ela tem a força de nos trazer de volta ao nosso mundo, revigorando-o, resgatando os entes de seu esquecimento.

Mas também em outro sentido a arte moderna e contemporânea é antiplatônica ou anti-classicista, na medida em que se permite trazer à representação pictórica até mesmo um objeto pouco nobre como um sapato... A tendência ao prosaísmo só vai se agravar com a arte contemporânea, o mictório de Duchamp é exemplar dela. No que diz respeito à dimensão prosaica, ousaria dizer que o discurso heideggeriano é para a filosofia o que Duchamp foi para as artes plásticas, isto é, "prosaização" elevada à máxima potência. Temos muitos exemplos dessa faceta beirando o ridículo dos textos de Heidegger. Ora, o caso da análise dos sapatos de Van Gogh está incluído certamente ali. Frente ao quadro de Van Gogh, Heidegger não hesita em fazer a pergunta: Afinal de contas, o que é um sapato? A ninguém passa desapercebido o tom um pouco ridículo da questão, não é mesmo? Mas será esse um dos inegáveis resultados da arte, da noção de obra de arte em Heidegger: circularmente, como é quase sempre o caso em Heidegger, o que define (mas o que também nos comove e surpreende) uma obra de arte é o fato de que ela seja (o verbo ser aqui tem valor intransitivo; não é verbo de ligação). E, exatamente porque ela (a obra de arte) é, é que ela é capaz de revelar, de um modo inaugural, inédito, nunca antes pensado, visto, sabido etc., as coisas que estão no mundo...

Voltando ao nosso cachimbo, poderíamos dizer que o cachimbo no quadro de Magritte é como nenhum cachimbo no mundo pode ser. Qualquer outro cachimbo no mundo será insuficiente para ser no sentido que só a obra de arte pode reivindicar ser.

\section{Post scriptum}

Certamente, em Heidegger, há uma espécie de glorificação e exaltação da arte, cuja contrapartida é um inevitável desprezo pela realidade. O pensamento de Heidegger exprime o sentimento típico de uma "época conceitual", na qual a realidade perdeu mesmo todo viço e vigor. A "revelação" que ocorre na obra de arte, mas também em outras experiências, como a filosófica e a política, não tem um sentido místico. Ao contrário, no quadro, revela-se somente o próprio ente, mas, sobretudo, na sua diferença com o ser. Justamente, nenhum 
Ser se apresenta aí. O que acontece a partir desse ponto tem a ver menos com o pensamento de Heidegger do que com a nossa época que vive, tal como, há muito tempo, Marx já havia diagnosticado, o predomínio do valor de troca em detrimento do valor de uso. Portanto, não é de se admirar o desvio que o argumento ontológico tomou na nossa triste história; o fato terrível que constitui o argumento ontológico da obra de arte ter acabado nas mãos do mercado, ter acabo por servir de "pedra de toque" ao mercado! Isso sim é que tratou de transformar a experiência estética em mística (para... valorizar ainda mais!)! Pois é um fato estrondosamente evidente que os sapatos pintados por Van Gogh (ainda mais por Van Gogh!) valem muito mais do que aqueles de couro ou de borracha, que podem ser tão confortáveis e aconchegantes, e que servem para não molharmos ou enchermos de lama os nossos pés... E que a mais-valia artística é o preço que se paga para comprar a imortalidade da alma. Por isso, o cachimbo, digamos assim, "ôntico", "real" que comprei no Mercado Central custou apenas 3,50 reais... Talvez porque ele não seja mais um cachimbo... 